\title{
Multicenter prospective study on predictors of short-term outcome in disorders of consciousness
}

Anna Estraneo, MD, Salvatore Fiorenza, NphT, Alfonso Magliacano, PsyD, Rita Formisano, MD, Donatella Mattia, MD, PhD, Antonello Grippo, MD, Anna Maria Romoli, MD, Efthymios Angelakis, MD, Helena Cassol, MD, Aurore Thibaut, PhD, Olivia Gosseries, PhD, Gianfranco Lamberti, MD, Enrique Noé, MD, PhD, Sergio Bagnato, MD, PhD, Brian L. Edlow, MD, Camille Chatelle, PhD, Nicolas Lejeune, MD, Vigneswaran Veeramuthu, PhD, Michelangelo Bartolo, MD, PhD, Jlenia Toppi, PhD, Nathan Zasler, MD, Caroline Schnakers, PhD, and Luigi Trojano, MD, on behalf of IBIA DoC-SIG

Neurology ${ }^{\circledR}$ 2020;95:e1488-e1499. doi:10.1212/WNL.0000000000010254

\author{
Correspondence \\ Dr. Estraneo \\ aestraneo@gmail.com
}

\section{Abstract \\ Objective}

This international multicenter, prospective, observational study aimed at identifying predictors of short-term clinical outcome in patients with prolonged disorders of consciousness (DoC) due to acquired severe brain injury.

\section{Methods}

Patients in vegetative state/unresponsive wakefulness syndrome (VS/UWS) or in minimally conscious state (MCS) were enrolled within 3 months from their brain injury in 12 specialized medical institutions. Demographic, anamnestic, clinical, and neurophysiologic data were collected at study entry. Patients were then followed up for assessing the primary outcome, that is, clinical diagnosis according to standardized criteria at 6 months postinjury.

\section{Results}

We enrolled 147 patients (44 women; mean age 49.4 [95\% confidence interval 46.1-52.6] years; VS/UWS 71, MCS 76; traumatic 55, vascular 56, anoxic 36; mean time postinjury 59.6 [55.4-63.6] days). The 6-month follow-up was complete for 143 patients (VS/UWS 70; MCS 73). With respect to study entry, the clinical diagnosis improved in 72 patients (VS/UWS 27; MCS 45). Younger age, shorter time postinjury, higher Coma Recovery Scale-Revised total score, and presence of EEG reactivity to eye opening at study entry predicted better outcome, whereas etiology, clinical diagnosis, Disability Rating Scale score, EEG background activity, acoustic reactivity, and P300 on event-related potentials were not associated with outcome.

\section{Conclusions}

Multimodal assessment could identify patients with higher likelihood of clinical improvement in order to help clinicians, families, and funding sources with various aspects of decision-making. This multicenter, international study aims to stimulate further research that drives international consensus regarding standardization of prognostic procedures for patients with DoC.

\footnotetext{
From IRCCS Fondazione Don Carlo Gnocchi (A.E., A.G., A.M.R.), Florence; Istituti Clinici Scientifici Maugeri IRCCS (S.F.), SB S.p.A., Laboratorio di Valutazione Multimodale dei Disordini della Coscienza, Telese Terme (BN); Department of Psychology (A.M., L.T.), University of Campania L. Vanvitelli, Caserta; Fondazione Santa Lucia IRCCS (R.F., D.M.), Rome, Italy; Neurosurgery Department (E.A.), University of Athens Medical School, Greece; Coma Science Group (H.C., A.T., O.G.), GIGA Consciousness, University and University Hospital of Liège, Belgium; Neurorehabilitation and Vegetative State Unit(G.L.), E. Viglietta, Cuneo, Italy; NEURORHB-Servicio de Neurorrehabilitación de Hospitales Vithas (E.N.), Valencia, Spain; Unit of Neurophysiology and Unit for Severe Acquired Brain Injuries (S.B.), Rehabilitation Department, Giuseppe Giglio Foundation, Cefalù, Italy; Center for Neurotechnology and Neurorecovery (B.L.E., C.C.), Department of Neurology, Massachusetts General Hospital, Boston; CHN William Lennox (N.L.), Ottignies, Belgium; Department of Psychology (V.V.), University of Reading Malaysia; Neurorehabilitation Unit (M.B.), HABILITA Zingonia/Ciserano, Bergamo; Department of Computer, Control and Management Engineering (.T.), Sapienza University of Rome, Italy; Concussion Care Centre of Virginia, Ltd. (N.Z.), Richmond; and Research Institute (C.S.), Casa Colina Hospital and Centers for Healthcare, Pomona, CA.
}

Go to Neurology.org/N for full disclosures. Funding information and disclosures deemed relevant by the authors, if any, are provided at the end of the article. 


\section{Glossary}

$\mathbf{A P G}=$ anterior-posterior gradient $\mathbf{A U C}=$ area under the curve $\mathbf{B C a}=$ bias corrected and accelerated $\mathbf{C I}=$ confidence interval; CRS-R = Coma Recovery Scale-Revised; DoC = Disorders of consciousness; DoC-SIG = Special Interest Group on Disorders of Consciousness; DRS = Disability Rating Scale; DS = diffuse slowing; ERP = event-related potential; IBIA = International Brain Injury Association; IPS = intermittent photic stimulation; LASSO = least absolute shrinkage and selection operator; LV = low voltage; $\mathbf{M C S}=$ minimally conscious state; $\mathbf{M i A}=$ mildly abnormal; $\mathbf{M o A}=$ moderately abnormal; NCS-R = Nociception Coma Scale-Revised; SEP = somatosensory evoked potential; VIF = variance inflation factor; VS/UWS = vegetative state/ unresponsive wakefulness syndrome.

Disorders of consciousness (DoC) - vegetative state/ unresponsive wakefulness syndrome (VS/UWS) ${ }^{1,2}$ and minimally conscious state $(\mathrm{MCS})^{3}$ - can persist for longer than 28 days (i.e., prolonged DoC). ${ }^{4}$ Reliable prognostic markers are necessary for assisting all involved parties on decisions about patient management. ${ }^{5,6}$ Many prognostic studies have investigated clinical and neurophysiologic indicators in comatose patients. ${ }^{7,8}$ Among these predictors, bilateral absence of the cortical component on somatosensory evoked potentials (SEPs) is considered the most accurate marker for poor prognosis in anoxic comatose patients. ${ }^{8,9}$ A recent study examined the prognostic value of SEPs in anoxic VS/UWS at 1-3 months after brain injury, ${ }^{10}$ confirming their utility in the rehabilitative setting. Recent longitudinal studies demonstrated the prognostic value of the Coma Recovery Scale-Revised (CRS-R $)^{10,11}$ and of EEG background activity ${ }^{12,13}$ in the subacute phase. However, the majority of these prognostic studies evaluated individual clinical or neurophysiologic predictors, an approach that precludes identification of the independent predictive role of each biomarker. ${ }^{14}$ Moreover, most of the available evidence for prognostication has been gathered in single-center studies that may be susceptible to sampling bias.

On this basis, the Special Interest Group on DoC (DoC-SIG) of the International Brain Injury Association (IBIA) (see internationalbrain.org) launched a multicenter, longitudinal study on a cohort of patients with prolonged DoC to evaluate the prognostic value of demographic, anamnestic, clinical, and multimodal neurophysiologic findings on clinical outcome at 6 months postinjury.

\section{Methods}

\section{Design of the study}

The present prospective, observational study was conducted in the framework of the IBIA DoC-SIG and involved 12 medical institutions with expertise in diagnosis and care of adults after severe acquired brain injuries. The participating units (intensive care units, $\mathrm{n}=2$; intensive specialized rehabilitation units for postacute patients, $\mathrm{n}=8$; neurology departments, $\mathrm{n}=2$ ) were located in Europe $(\mathrm{n}=10)$, North America $(\mathrm{n}=1)$, and Asia $(\mathrm{n}=1)$.

The study was conducted in 3 phases. In the first phase, a team of multidisciplinary investigators from all participating sites identified clinical and neurophysiologic measures that are feasible to collect in most clinical settings ${ }^{10,12,13,15-17}$ and potentially informative for the purposes of the study, as suggested by recent recommendation statements for prognosis in adults with prolonged DoC. ${ }^{4}$ All participating centers had wellestablished expertise in using the selected clinical and neurophysiologic tools. In the second phase, the skilled examiners, selected among the staff of each participating center for their long-standing experience in the evaluation of patients with DoC, participated in several conference calls to ensure the consistency of administration and scoring of the clinical scales, as well as of acquisition and analysis of the neurophysiologic tests selected for the study. In the third phase, all participating centers enrolled a convenience sample of patients with prolonged DoC from January to December 2017 and followed them clinically until 6 months after brain injury.

\section{Study population}

Inclusion criteria were (1) age 18-80 years; (2) clinical diagnosis of VS/UWS or MCS, according to standard diagnostic criteria $^{1,3}$; (3) anoxic, traumatic, or vascular (i.e., hemorrhagic or ischemic) etiology; (4) time postinjury ranging from 1 to 3 months. Exclusion criteria were (1) previous history of acquired brain injury or psychiatric or neurodegenerative diseases; (2) coexisting neoplasms, severe organ dysfunction, or unstable clinical condition (e.g., hemodynamic instability or severe respiratory failure).

\section{Clinical assessment}

At study entry, each center collected patient demographic data (e.g., age, sex) and information about medical history (e.g., etiology, time postinjury). Within 1 week from study entry, all patients were assessed by skilled investigators by means of repeated (at least 3 in a week) CRS-R evaluations ${ }^{15}$ in order to confirm the patients' clinical diagnosis ${ }^{18}$ and to determine the best CRS-R total score. Moreover, hospital staff assessed patients' behavioral response to nociceptive stimuli and functional disability level by means of the Nociception Coma Scale-Revised $(\text { NCS-R })^{19}$ and Disability Rating Scale (DRS) ${ }^{20}$ total scores, respectively. Patients were clinically followed up at 6 months after brain injury by repeated CRS-R conducted by the same clinical staff from their hospital stay or, if after discharge, in an outpatient follow-up clinic, at home, or in chronic care facilities.

\section{Neurophysiologic examination}

Skilled neurophysiologists blind to the patient's clinical diagnosis recorded and analyzed multimodal neurophysiologic 
data including standard EEG, SEPs, and event-related potentials (ERPs) within 15 days from study entry, according to the shared protocols.

The standard EEG was recorded by 19 electrodes placed on the patients' scalp according to the international 10-20 system (Fp1, Fp2, F7, F8, F3, F4, C3, C4, T3, T4, P3, P4, T5, T6, O1, $\mathrm{O} 2, \mathrm{Fz}, \mathrm{Cz}, \mathrm{Pz}$ ). EEG was recorded for a minimum of 35 minutes according to standard procedure of eye-closed recording during a waking rest with filter settings $0.53-70 \mathrm{~Hz}$ and notch filter on. Eyes closure for the analysis of predominant activity was obtained with forced eye closing by a cotton wool applied by paper patch in wakefulness condition (spontaneous eye opening). A morning EEG was acquired bedside after customary nursing procedures and (at least) 10 hours after administration of drugs acting on the CNS, such as myorelaxants and sedative drugs (e.g., benzodiazepines, neuroleptics) in order to optimize vigilance. Long-term antiepileptic treatment was continued, if clinically indicated.

EEG background activity was classified into 5 severity categories according to recently proposed criteria for patients with $\mathrm{DoC}^{21}$ : (1) normal EEG activity, in presence of predominant posterior alpha rhythm and of the anterior-posterior gradient (APG), without focal or hemispheric slowing or epileptiform abnormalities; (2) mildly abnormal (MiA) EEG, characterized by predominant posterior theta activity $(>20 \mu \mathrm{V})$, symmetric or not, with frequent (10\%-49\% of recording) posterior alpha rhythms; (3) moderately abnormal (MoA) EEG, characterized by predominant posterior theta activity $(>20 \mu \mathrm{V})$, symmetric or not, poorly organized APG, even with rare ( $<1 \%$ of recording) or occasional (1\%-9\% of recording) posterior alpha rhythms; (4) diffuse slowing (DS), defined as an EEG background activity with predominant diffuse theta or theta/delta rhythms at amplitude $>20 \mu \mathrm{V}$, without APG; (5) low voltage (LV) EEG, defined as a predominant EEG activity (theta or delta) $<20 \mu \mathrm{V}$ over most brain regions.

To analyze EEG reactivity to external stimulation, 5 kinds of stimuli were randomly administered (each stimulus 3 times) during EEG recording: (1) eye opening and (forced) eye closing; (2) tactile stimuli (wiping on the back of right and left forearm with cotton wool); (3) noxious stimulation (pressing fingernail beds on each hand); (4) acoustic stimulation (hand clapping); (5) intermittent photic stimulation (IPS) by 1, 3, 6, $9,12,15,18$, and $21 \mathrm{~Hz}$ flashes in 10-second trains presented through closed eyelids with 5 -second interval between 2 trains. We analyzed 3-second EEG activity after stimulus onset to detect any clear and reproducible change in frequency or amplitude in cerebral activity that could be ascribed to multisensory stimulation. ${ }^{22}$ EEG reactivity to each kind of stimulus was defined as present if it was recorded in at least one out of 3 trials. The effect of IPS was considered as present if the physiologic photic driving response was elicited over posterior region. Not clearly detectable EEG responses to stimuli were considered as absent. If artifacts were present in more than $50 \%$ of EEG recording time, EEG acquisition was repeated within 1 week. When no EEG of sufficient quality could be obtained, EEG data were excluded from analysis.

SEPs were recorded during electrical stimulation of the patients' median nerve, delivered by means of a bipolar surface electrode placed on the patients' right and left wrists. Stimulation intensity was set to $4 / 3$ of individual motor threshold. Each pulse lasted $0.2 \mathrm{~ms}$ and was delivered with a $3 \mathrm{~Hz}$ rate (time base $50 \mathrm{~ms}$; bandwidth $5 \mathrm{~Hz}-3 \mathrm{KHz}$ ). Recording stainless steel needle electrodes or silver cups were placed at Erb's point (referred to contralateral Erb's point), spinous process Cv7 (referred to anterior neck), C3' and C4' (referred to each other and to $\mathrm{Fz}$ ). At least 2 averages of 300 responses were repeated and superimposed. The presence or absence of N20/P25 cortical components was evaluated. ${ }^{23}$

ERPs were obtained by means of a simple oddball paradigm using auditory stimulation. ${ }^{24}$ Two randomly intermixed tones (not-target: $1,000 \mathrm{~Hz}$, overall probability $80 \%$; target: $2,000 \mathrm{~Hz}$, overall probability $20 \%$ ) were delivered binaurally through earphones at a rate of 1 tone ( $90 \mathrm{~dB}$ SPL, $50 \mathrm{~ms}$ plateau time, 2 $\mathrm{ms}$ rise and fall slope) every 1.1 seconds. Each patient was asked to keep a mental count of the rare (target) tones while ignoring the frequent (not-target) tones. This procedure was conducted independently of patients' language comprehension abilities on the behavioral examination. ${ }^{25}$ EEG activity was continuously recorded (band pass filtered at $0.1-100 \mathrm{~Hz}$; digitized at a sampling rate of $1,024 \mathrm{~Hz})$ from at least $3(\mathrm{Fz}, \mathrm{Cz}$, and $\mathrm{Pz})$ scalp electrodes (10-20 International System) all referred to linked earlobes, with the ground electrode positioned on Fpz. In the presence of a N100, detection of late cortical component P300 was evaluated by visual identification by a trained neurophysiologist based on latency (280-500 ms) and scalp topography central to parietal $(80-150 \mathrm{~ms}) .^{24}$

\section{Outcome definition}

The primary outcome was a patient's clinical diagnosis at 6 months postinjury. Clinical diagnosis was established according to the standardized clinical criteria for VS/UWS, ${ }^{1,2}$ MCS, and for emergence from MCS, ${ }^{3}$ confirmed by CRS-R ${ }^{4}$ For the purpose of statistical analysis, we classified a patient as improved if there was an improvement in clinical diagnosis with respect to study entry (i.e., patient in MCS at baseline who emerged from MCS, and patient in VS/UWS at baseline who progressed to MCS or eventually regained full consciousness). We classified a patient as not improved if the clinical diagnosis worsened (i.e., patient in MCS at baseline who worsened to VS/UWS), or did not improve, or if the patient died.

\section{Data management and statistical analyses}

Referring staff from all participating sites entered, through a forced-choice format, patient data into a secure, passwordprotected, electronic database uploaded onto a shared folder. Data entry fields for each patient were referred to by an anonymous code that did not allow the identity of the patient to be traced, in order to protect confidentiality and to safeguard privacy. Regular checks on data entry were periodically carried out 
by the coordinator research group (A.E., S.F., A.M.). If any missing data or inconsistencies were detected, the center in question was encouraged to check it thoroughly. When completed, the database was removed from the online shared folder and kept on file safely stored by the principal investigator (A.E.).

Statistical analyses were performed by the coordinator researcher group (A.E., A.M., L.T.). Descriptive statistics were presented as means and 95\% confidence intervals (CIs) for continuous variables and as frequencies for categorical variables. For between-group comparisons, continuous variables were submitted to Shapiro-Wilk test for normality. As scores of several variables departed significantly from the norm, we compared baseline findings as a function of diagnosis (VS/ UWS vs MCS), of etiology, and of outcome (improved vs not improved) by nonparametric Mann-Whitney $U$ test for continuous variables and $\chi^{2}$ for categorical variables. The level of significance was adjusted for multiple comparisons using the false discovery rate correction; corrected $p$ was set at 0.05 (2tailed). Effect size for nonparametric statistics was expressed as $\eta^{2}(95 \% \mathrm{CI})$, and for $\chi^{2}$ statistics as Cramer V (95\% CI), computed by means of a bootstrapping procedure $(1,000$ samples; $\mathrm{CI}=\mathrm{BCa}$ [bias corrected and accelerated]). The results were considered statistically significant when corrected $p$ was $<0.05$ and $0<\eta^{2} / \mathrm{V}(95 \% \mathrm{CI})<1$.

To investigate the relationships between predictors at baseline and outcome at 6 months postinjury, we applied 2 regression models. Prior to any regression analysis, we tested multicollinearity among the predictors by checking for the variance inflation factor (VIF) and tolerance. A VIF value less than 10 or tolerance (that is, the inverse of the VIF) less than 0.1 should not involve any issues with multicollinearity; in general, the lower the VIF value, the smaller the correlation among variables. ${ }^{26}$

Then, we used a standard logistic regression model in which we included the selected variables as independent predictors and the outcome (improved $=1$; not improved $=0$ ) as the dependent variable. However, since standard regression models might suffer from overfitting, we also used a penalized regression model (least absolute shrinkage and selection operator [LASSO]) as an additional analysis. In the LASSO model, coefficients are biased from a penalty term in order to increase the predictive accuracy. The applied penalty could shrink to zero and then pull out from the final model factors whose original predictive value was low, thus including only the most important variables. The degree of shrinkage was determined by a 10 -fold cross-validation. No $p$ values are reported for the LASSO method, which does not provide tests of significance, whereas we reported model fit accuracy for both logistic and LASSO regression models. Moreover, model fit for the logistic regression was assessed by means of the Hosmer-Lemeshow goodness of fit test, for which a $p$ value less than 0.05 suggests a poor fit. The Nagelkerke pseudo$R^{2}$, which indicates the amount of variability accounted by all predictors in the model, was also computed. For evaluating the discrimination ability of the logistic regression model, the area under the curve (AUC) of the receiver operating characteristic curve was obtained. Accuracy of predictors of the logistic regression model was also assessed by a bootstrapping procedure (1,000 samples; $\mathrm{CI}=95 \%$; $\mathrm{BCa})$.

All continuous variables were standardized prior to regression analyses. Moreover, as the LASSO model only deals with dichotomic categorical variables, and for the sake of consistency, in both the standard and the LASSO regressions multichotomic variables categorized as follows. For etiology, we contrasted traumatic vs nontraumatic (i.e., anoxic and vascular) brain injury, as often found in the literature. ${ }^{1,6}$ As regards background EEG patterns and consistent with recent literature, ${ }^{21}$ we contrasted patterns with residual alpha rhythm (normal, MiA, MoA) vs patterns lacking alpha rhythm (DS, LV). Possible missing data were handled by listwise deletion. As this conservative procedure model limited the analysis to patients for whom all relevant data were available, we had to perform the same regression analyses twice, including or excluding ERP as an independent variable (ERPs were available for a subset of patients; see below). The level of significance was set at 0.05 (2-tailed).

In presenting the results, we focused on the logistic regression model and added the LASSO results as auxiliary; moreover, we also presented the main concordances and discordances between the logistic and the LASSO model. Statistical analyses were performed by IBM SPSS Statistics v. 25 (IBM Corp., Armonk, NY) and R version 3.5.3 (R Foundation for Statistical Computing, Vienna, Austria), including the $\mathrm{R}$ packages glmnet and caret for the LASSO model.

\section{Standard protocol approvals and patient consents}

The institutional review board of the coordinating center and of each center involved in the study reviewed and approved the same outline of the project, shared by all centers and translated in the respective languages. This study was then approved by the ethical standards committee of the coordinator center and of each center involved in the study, and performed according to the ethical standards of the Declaration of Helsinki (1964) and its later amendments. The surrogate decision-makers of the patients enrolled in the study provided their written informed consent after a semiformalized interview in which the purposes, procedures, and time points of the longitudinal study were clearly explained. The original forms were collected and stored at each participant center.

\section{Data availability}

Any anonymized data not published within the article will be shared upon request from any qualified investigator.

\section{Results}

\section{Patient sample}

Out of 194 patients screened for the study, 147 patients with DoC fulfilled the selection criteria (figure). Demographic and 
Figure Study flowchart

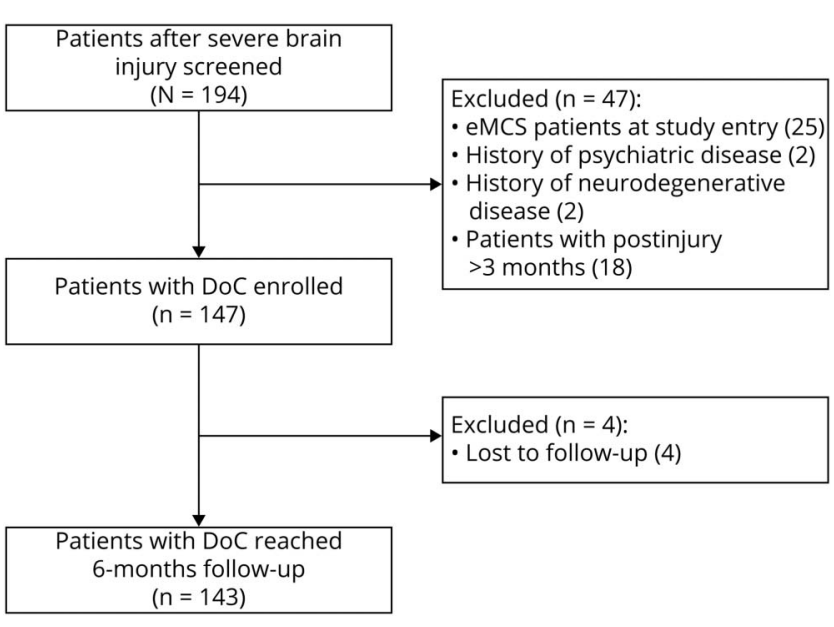

DoC $=$ disorders of consciousness; eMCS = emergence from minimally conscious state.

clinical data for each diagnostic group are reported in table 1. Patients in MCS showed significantly higher total scores for CRS-R $\left(U=132.0\right.$; corrected $\left.p<0.001 ; \eta^{2}=0.68[0.62-0.74]\right)$ and NCS-R $\left(U=1,261.5\right.$; corrected $p<0.001 ; \eta^{2}=0.22$ [0.16-0.27] ) and lower scores for DRS $(U=942.5$; corrected $p$ $<0.001 ; \eta^{2}=0.32[0.27-0.38]$ ) than patients in VS/UWS; patients in MCS did not differ from patients in VS/UWS in terms of age, sex, etiology, or time postinjury (all corrected $p>$ 0.1 ). Regarding etiology, patients with traumatic brain injury were significantly younger than patients with anoxic brain injury $\left(U=365.0\right.$; corrected $\left.p<0.001 ; \eta^{2}=0.28[0.19-0.37]\right)$ and vascular insults $\left(U=393.5\right.$; corrected $p<0.001 ; \eta^{2}=0.41$ [0.34-0.49]; table 1).

Neurophysiologic findings (available data: EEG background activity $=94.5 \%$; reactivity to eye opening $=93.9 \%$; reactivity to tactile stimulation $=88.4 \%$; reactivity to acoustic stimulation $=$ 95.2\%; reactivity to nociceptive stimulation $=87.7 \%$; reactivity to IPS $=90.4 \%$; SEP $=58.5 \%$; ERP $=53.6 \%$; table 2) showed that the frequency of normal, MiA, MoA, DS, and LV patterns of EEG background activity significantly differed between MCS and VS/UWS $\left(\chi_{4,139}^{2}=25.36\right.$; corrected $p<0.001 ; \mathrm{V}=0.42$ $[0.29-0.61])$, and among the 3 etiologies, as a better EEG background organization was observed in MCS with respect to VS/UWS and in traumatic $\left(\chi_{4,139}^{2}=32.92\right.$; corrected $p<$ $0.001 ; \mathrm{V}=0.62[0.43-0.80])$ and vascular $\left(\chi_{4,139}^{2}=36.60\right.$; corrected $p<0.001 ; \mathrm{V}=0.63$ [0.46-0.80]) etiology vs anoxic brain injury. EEG reactivity to eye opening and closing was more frequent in traumatic than in anoxic patients $\left(\chi_{1,138}^{2}=\right.$ 7.59; corrected $p=0.006 ; \mathrm{V}=0.30$ [0.09-0.47]), whereas reactivity to acoustic, tactile, nociceptive, and intermittent photic stimulations did not differ among diagnostic and etiologic groups. The cortical component P300 on ERP was significantly more frequent in MCS than in VS/UWS $\left(\chi_{1,75}^{2}=\right.$ 8.13; corrected $p=0.004 ; \mathrm{V}=0.32$ [0.12-0.53]; table 2).

\section{Clinical evolution at 6-month follow-up}

The 6-month follow-up (mean days from the brain injury = $180.31 \pm 11.27)$ was complete for 143 patients $(97.2 \%$ of the sample). Four patients dropped out from the study because of transfer to other care institution/home $(n=2)$ or revoked legal guardians' consent for study participation $(n=2)$. Seventy-one patients (49.6\%) were classified as not improved; among them, 4 patients declined from MCS to VS/UWS (5.6\%), 52 patients

Table 1 Demographic and clinical characteristics of patients at study entry as a function of diagnosis and etiology

\begin{tabular}{|c|c|c|c|c|c|c|}
\hline & \multirow[b]{2}{*}{ Total } & \multicolumn{2}{|c|}{ Clinical diagnosis } & \multicolumn{3}{|l|}{ Etiology } \\
\hline & & VS/UWS & MCS & Traumatic & Vascular & Anoxic \\
\hline $\mathbf{N}$ & 147 & 71 & 76 & 55 & 56 & 36 \\
\hline Age, $y^{a}$ & $49.4(46.1-52.6)$ & $51.7(47.1-56.3)$ & $47.2(42.6-51.9)$ & $33.8(29.3-38.3)$ & $60.5(56.6-64.4)$ & $55.9(50.4-61.4)$ \\
\hline F/M & $44 / 103$ & $21 / 50$ & $23 / 53$ & $11 / 44$ & $22 / 34$ & $11 / 25$ \\
\hline $\begin{array}{l}\text { Clinical diagnosis, } \\
\text { VS-UWS/MCS }\end{array}$ & - & - & - & $23 / 32$ & $26 / 30$ & $22 / 14$ \\
\hline TPI, d & $59.6(55.4-63.6)$ & $59.8(53.7-65.9)$ & $59.4(53.7-65.1)$ & $59.9(52.8-67.0)$ & $57.8(51.0-64.6)$ & $61.9(53.8-69.9)$ \\
\hline CRS-R total score ${ }^{\mathrm{b}}$ & $8.6(7.8-9.4)$ & $4.6(4.2-5.0)$ & $12.4(11.6-13.3)$ & $9.6(8.1-11.0)$ & $8.6(7.3-9.9)$ & $7.3(5.9-8.7)$ \\
\hline NCS-R total score ${ }^{b}$ & $2.9(2.6-3.2)$ & $2.1(1.8-2.4)$ & $3.7(3.3-4.1)$ & $3.2(2.7-3.7)$ & $2.7(2.3-3.2)$ & $2.8(2.2-3.4)$ \\
\hline DRS total score ${ }^{b}$ & $23.8(23.3-24.3)$ & $25.4(25.0-25.9)$ & $22.3(21.7-23.0)$ & $23.2(22.5-24.0)$ & $24.0(23.1-24.8)$ & $24.6(23.8-25.3)$ \\
\hline
\end{tabular}

Abbreviations: $\mathrm{Cl}$ = confidence interval; $\mathrm{CRS}-\mathrm{R}=$ Coma Recovery Scale-Revised; DRS = Disability Rating Scale; FDR = false discovery rate; MCS = minimally conscious state; NCS-R = Nociception Coma Scale-Revised; TPI = time postinjury; VS/UWS = vegetative state/unresponsive wakefulness syndrome.

Descriptive data are reported as mean $(95 \% \mathrm{CI})$ for continuous variables and as counts for categorical variables. Univariate statistics are based upon the Mann-Whitney test or $\chi^{2}$ test, as appropriate, and relative effect size.

a Significant differences among etiologic groups for FDR-corrected $p<0.05$ rate and for $0<\eta^{2} / \mathrm{N}(95 \% \mathrm{Cl})<1$.

b Significant differences between diagnostic groups for FDR-corrected $p<0.05$ rate and for $0<\eta^{2} / \mathrm{V}(95 \% \mathrm{Cl})<1$. 
Table 2 Distribution of neurophysiologic findings at study entry as a function of diagnosis and etiology

\begin{tabular}{|c|c|c|c|c|c|c|}
\hline & \multirow[b]{2}{*}{ Total } & \multicolumn{2}{|c|}{ Clinical diagnosis } & \multicolumn{3}{|l|}{ Etiology } \\
\hline & & VS/UWS & MCS & Traumatic & Vascular & Anoxic \\
\hline EEG background activity ${ }^{a, b}$ & 139 & 69 & 70 & 49 & 54 & 36 \\
\hline Normal & 6 & 0 & 6 & 2 & 4 & 0 \\
\hline Mildly abnormal & 27 & 5 & 22 & 15 & 8 & 4 \\
\hline Moderately abnormal & 35 & 17 & 18 & 17 & 16 & 2 \\
\hline Diffuse slowing & 45 & 32 & 13 & 12 & 24 & 9 \\
\hline Low voltage & 26 & 15 & 11 & 3 & 2 & 21 \\
\hline Reactivity to eye opening, $P / A^{b}$ & $43 / 95$ & $16 / 53$ & $27 / 42$ & $20 / 28$ & $18 / 36$ & $5 / 31$ \\
\hline Reactivity to tactile stimuli, P/A & $19 / 111$ & $10 / 58$ & $9 / 53$ & $4 / 41$ & $8 / 46$ & $7 / 24$ \\
\hline Reactivity to acoustic stimuli, P/A & $35 / 105$ & $13 / 56$ & $22 / 49$ & $13 / 37$ & $17 / 37$ & $5 / 31$ \\
\hline Reactivity to nociceptive stimuli, P/A & $34 / 95$ & $16 / 51$ & $18 / 44$ & $9 / 36$ & $18 / 36$ & $7 / 23$ \\
\hline Reactivity to IPS, P/A & $25 / 108$ & $15 / 53$ & $10 / 55$ & $8 / 40$ & $11 / 43$ & $6 / 25$ \\
\hline N20 on SEP, P/A & $65 / 21$ & $32 / 15$ & $33 / 6$ & $17 / 12$ & $29 / 4$ & $19 / 5$ \\
\hline P300 on ERP, P/A & $40 / 35$ & $12 / 22$ & $28 / 13$ & $11 / 10$ & $21 / 13$ & $8 / 12$ \\
\hline
\end{tabular}

Abbreviations: $\mathrm{Cl}$ = confidence interval; $\mathrm{ERP}$ = event-related potential; $\mathrm{FDR}$ = false discovery rate; $\mathrm{MCS}$ = minimally conscious state; IPS = intermittent photic stimulation; $\mathrm{P} / \mathrm{A}$ = present/absent; SEP = somatosensory evoked potential; VS/UWS = vegetative state/unresponsive wakefulness syndrome.

Data are reported as counts. Univariate statistics are reported based upon the $\chi^{2}$ test and relative effect size.

a Significant differences between diagnostic groups for FDR-corrected $p<0.05$ rate and for $0<\mathrm{V}(95 \% \mathrm{Cl})<1$.

${ }^{\mathrm{b}}$ Significant differences among etiologic groups for FDR-corrected $p<0.05$ rate and for $0<\mathrm{V}(95 \% \mathrm{Cl})<1$.

(32 in VS/UWS, 45.0\%; 20 in MCS, 28.2\%) did not change their clinical diagnosis, and 11 patients in VS/UWS (15.5\%) and 4 in MCS (5.6\%) died. No patients died because of withdrawal of life-sustaining therapy ${ }^{27}$; death was due to severe medical complications (e.g., sepsis, acute respiratory distress, gastrointestinal bleeding, cardiac arrest) despite life-sustaining treatments. Among the 72 patients $(50 \%)$ classified as improved, 20 in VS/UWS at baseline progressed to MCS

Table 3 Demographic and clinical characteristics of patients at study entry as a function of 6-month outcome

\begin{tabular}{|c|c|c|c|c|}
\hline & Total $(n=143)$ & Not improved $(n=71)$ & Improved $(n=72)$ & $\eta^{2} / \mathrm{V}(95 \% \mathrm{Cl})$ \\
\hline Age, y & $49.8(46.6-53.1)$ & $55.4(50.9-59.9)$ & $44.4(40.0-48.8)$ & $0.08(0.02 \text { to } 0.13)^{a}$ \\
\hline F/M & $42 / 101$ & $27 / 44$ & $15 / 57$ & $0.18(0.03 \text { to } 0.34)^{a}$ \\
\hline Clinical diagnosis, VS-UWS/MCS & $70 / 73$ & $43 / 28$ & $27 / 45$ & $0.23(0.06 \text { to } 0.39)^{a}$ \\
\hline Etiology & & & & $0.26(0.09 \text { to } 0.44)^{a}$ \\
\hline Traumatic & 52 & 18 & 34 & \\
\hline Vascular & 55 & 28 & 27 & \\
\hline Anoxic & 36 & 25 & 11 & \\
\hline TPI, d & $59.3(55.2-63.5)$ & $67.0(61.2-72.8)$ & $51.8(46.2-57.4)$ & $0.1(0.04 \text { to } 0.15)^{a}$ \\
\hline CRS-R total score & $8.5(7.7-9.3)$ & $6.8(6.0-7.8)$ & $10.1(8.9-11.3)$ & $0.11(0.05 \text { to } 0.16)^{a}$ \\
\hline NCS-R total score & $2.9(2.6-3.2)$ & $2.6(2.3-3.0)$ & $3.1(2.7-3.5)$ & $0.02(-0.04$ to 0.07 \\
\hline DRS total score & $23.9(23.4-24.3)$ & $24.6(24.2-25.1)$ & $23.1(22.3-23.9)$ & $0.07(0.01 \text { to } 0.12)^{a}$ \\
\hline
\end{tabular}

Abbreviations: $\mathrm{Cl}$ = confidence interval; $\mathrm{CRS}-\mathrm{R}=$ Coma Recovery Scale-Revised; DRS = disability rating scale; FDR = false discovery rate; $\mathrm{MCS}=$ minimally conscious state; NCS-R = Nociception Coma Scale-Revised; TPI = time postinjury; VS/UWS = vegetative state/unresponsive wakefulness syndrome.

Descriptive data are reported as mean $(95 \% \mathrm{Cl})$ for continuous variables and as counts for categorical variables. Univariate statistics are based upon the Mann-Whitney test or $\chi^{2}$ test, as appropriate, and relative effect size.

a Significant variables (based on FDR-corrected $p<0.05$ rate and on $0<\eta^{2} / V[95 \% \mathrm{Cl}]<1$ ) and relative effect size. 
Table 4 Neurophysiologic findings at baseline as a function of 6-month outcome

\begin{tabular}{|c|c|c|c|c|}
\hline & Total & Not improved & Improved & $\mathrm{V}(95 \% \mathrm{Cl})$ \\
\hline EEG background activity & 137 & 68 & 69 & $0.35(0.16-0.56)^{a}$ \\
\hline Normal & 6 & 2 & 4 & \\
\hline Mildly abnormal & 27 & 9 & 18 & \\
\hline Moderately abnormal & 35 & 12 & 23 & \\
\hline Diffuse slowing & 44 & 25 & 19 & \\
\hline Low voltage & 25 & 20 & 5 & \\
\hline Reactivity to eye opening, P/A & $43 / 93$ & $12 / 55$ & $31 / 38$ & $0.29(0.12-0.44)^{\mathrm{a}}$ \\
\hline Reactivity to tactile stimuli, P/A & $19 / 110$ & $9 / 53$ & $10 / 57$ & $0.00(0.00-0.00)$ \\
\hline Reactivity to acoustic stimuli, P/A & $35 / 101$ & $10 / 57$ & $25 / 44$ & $0.24(0.07-0.38)^{\mathrm{a}}$ \\
\hline Reactivity to nociceptive stimuli, P/A & $33 / 95$ & $14 / 47$ & $19 / 48$ & $0.06(0.00-0.27)$ \\
\hline Reactivity to IPS, P/A & $25 / 107$ & $11 / 54$ & $14 / 53$ & $0.05(0.00-0.27)$ \\
\hline N20 on SEP, P/A & $65 / 21$ & $31 / 12$ & $34 / 9$ & $0.08(0.00-0.34)$ \\
\hline P300 on ERP, P/A & $39 / 35$ & $13 / 23$ & $26 / 12$ & $0.32(0.08-0.54)^{a}$ \\
\hline
\end{tabular}

Abbreviations: $\mathrm{Cl}$ = confidence interval; ERP = event-related potential; FDR = false discovery rate; IPS = intermittent photic stimulation; P/A = present/absent; SEP = somatosensory evoked potential.

Data are reported as counts. Univariate statistics are reported based upon the $\chi^{2}$ test and relative effect size.

${ }^{a}$ Significant variables (based on FDR-corrected $p<0.05$ rate and on $0<\mathrm{V}[95 \% \mathrm{Cl}]<1$ ) and relative effect sizes.

(27.8\%), whereas 7 patients in VS/UWS at baseline (9.7\%) and 45 patients in MCS at baseline (62.5\%) emerged from MCS.

\section{Predictors of 6-month outcome}

Univariate analyses showed that improved patients had significantly younger age $(U=1,729.0$; corrected $p=0.001)$ and shorter time postinjury $(U=1,632.5$; corrected $p<0.001)$ at study entry than patients who did not improve. Moreover, better 6-month prognosis was associated with male sex $\left(\chi_{1,143}^{2}\right.$ $=5.09$; corrected $p=0.02)$, MCS diagnosis $\left(\chi_{1,143}^{2}=7.60\right.$; corrected $p=0.006)$, and traumatic etiology $\left(\chi_{2,143}^{2}=10.37\right.$; corrected $p=0.006)$. Improved patients had higher CRS-R total score $(U=1,592.0$; corrected $p<0.001)$ and lower DRS total score $(U=1799.0$; corrected $p=0.002)$ at study entry than patients who did not improve, whereas the 2 prognostic groups did not differ in the NCS-R total score (corrected $p>$ 0.1 ; table 3).

Regarding the neurophysiologic findings (table 4), the patterns of EEG background activity significantly differed between improved and not improved patients $\left(\chi_{4,137}^{2}=16.93\right.$; corrected $p$ $=0.002$ ), as better EEG background organization at baseline was associated with better outcome. Moreover, EEG reactivity to eye opening and closing $\left(\chi_{1,136}^{2}=11.47\right.$; corrected $p=$ $0.001)$ and to acoustic stimuli $\left(\chi_{1,136}^{2}=8.07\right.$; corrected $p=$ $0.004)$ was significantly more frequent in patients who improved, whereas reactivity to tactile, nociceptive, and intermittent photic stimulations did not discriminate between the outcomes (all corrected $p>0.1$ ). The presence of cortical component P300 on ERP was significantly more frequent in improved patients $\left(\chi_{1,74}^{2}=7.74\right.$; corrected $\left.p=0.005\right)$, whereas the presence of N20 wave on SEP was not associated with outcome (corrected $p>0.1$ ).

Prior to performing regression analyses, we verified that no collinearity issues were present among the selected predictors (VIF ranging from 1.10 to 4.53 ; tolerance values ranging from 0.22 to 0.90$)$.

Standard logistic regression analysis on improvement of clinical diagnosis with age, sex, etiology, time postinjury, entry diagnosis, CRS-R and DRS total scores, EEG background activity, EEG reactivity to eye opening and to acoustic stimuli, and ERP as predictors was performed on 72 patients in whom all data were collected. Regression analysis provided a significant final model (likelihood ratio $\chi^{2}=53.36, d f=11, p<0.001$ ) with $87.5 \%$ accuracy. In this model, younger age, shorter time postinjury, higher CRS-R total score, and presence of EEG reactivity to eye opening were significantly associated with a better outcome, whereas sex, etiology, clinical diagnosis, DRS total score, EEG background activity and reactivity to acoustic stimuli, and presence of P300 on ERP at study entry were not (table 5). The bootstrapping results were deemed to be very biased (biases ranging from -416.34 to 218.83 ). However, this logistic regression showed a good model fit as indicated by the Hosmer-Lemeshow test $(p=0.11)$. Predictors in this model accounted for the $69.9 \%$ of variability in the model (Nagelkerke pseudo- $R^{2}=0.699$ ), and AUC was 0.94 (95\% CI [0.89-0.99]). The LASSO model provided a similar model fit accuracy (87.5\%) and substantially confirmed the logistic regression 
Table 5 Standard logistic regression model with associated least absolute shrinkage and selection operator (LASSO) coefficients for predicting improvement at 6-month follow-up $(n=72)$

\begin{tabular}{lllll}
\hline Factor & Reference & $\beta$ & LASSO $\beta$ & -1.10 \\
\hline Age & & -1.91 & $0.14(0.04-0.53)^{\mathrm{a}}$ \\
\hline Male sex & $\mathrm{F}$ & 1.15 & 0.84 & $0.15(0.47-21.11)$ \\
\hline Etiology (traumatic) & Nontraumatic & -0.63 & $0.53(0.06-4.42)$ \\
\hline TPI & & -2.26 & -1.33 & $0.10(0.02-0.39)^{\mathrm{a}}$ \\
\hline Diagnosis (MCS) & VS/UWS & -4.00 & -0.94 & $0.01(0.00-1.04)$ \\
\hline CRS-R & & 2.20 & 0.66 & $9.10(1.17-70.30)^{\mathrm{a}}$ \\
\hline DRS & & -1.07 & -0.45 & $0.34(0.11-1.02)$ \\
\hline EEG background (alpha) & Slow & -1.85 & -0.79 & $0.15(0.01-1.35)$ \\
\hline EEG-R eye (present) & Absent & 2.30 & 1.33 & $10.04(1.07-94.10)^{\mathrm{a}}$ \\
\hline EEG-R acoustic (present) & Absent & 0.71 & 0.10 & $2.03(0.22-18.43)$ \\
\hline P300 (present) & Absent & 0.92 & 0.59 & $2.51(0.37-16.80)$ \\
\hline
\end{tabular}

Abbreviations: $\mathrm{Cl}$ = confidence interval; CRS-R = Coma Recovery Scale-Revised; DRS = Disability Rating Scale; EEG-R = EEG reactivity; MCS = minimally conscious state; OR = odds ratio; TPI = time postinjury; VS/UWS = vegetative state/unresponsive wakefulness syndrome.

Out of 72 patients included in the analysis (VS/UWS = 33; MCS = 39), 38 improved at 6 months after brain injury (VS/UWS = 17; MCS = 21).

a Significant factors and relative OR.

model, since etiology was the only predictor whose coefficient was shrunk to zero (table 5).

As the previous model was based on a subset of patients for whom all relevant data were available, we repeated the same statistical analyses excluding ERP as an independent variable. The new analysis included data from 135 patients and provided a significant final model (likelihood ratio $\chi^{2}=72.06, d f=10, p<$ 0.001 ), with an $80.7 \%$ accuracy. In line with the previous results, this new model (table 6) showed that younger age, shorter time postinjury, higher CRS-R total score, and presence of EEG reactivity to eye opening at study entry were significantly associated with a better outcome, whereas sex, etiology, clinical diagnosis, DRS total score, EEG background activity,

Table 6 Standard logistic regression model with associated least absolute shrinkage and selection operator (LASSO) coefficients for predicting improvement at 6-month follow-up without event-related potentials among the independent variables $(n=135)$

\begin{tabular}{|c|c|c|c|c|}
\hline Factor & Reference & $\beta$ & LASSO $\beta$ & OR $(95 \% \mathrm{CI})$ \\
\hline Age & & -1.32 & $-0.81^{a}$ & $0.26(0.12-0.54)^{a}$ \\
\hline Male sex & $\mathrm{F}$ & 0.85 & 0.60 & $2.35(0.85-6.45)$ \\
\hline Etiology (traumatic) & Nontraumatic & -0.46 & 0 & $0.62(0.17-2.18)$ \\
\hline TPI & & -1.30 & -0.85 & $0.27(0.14-0.50)^{\mathrm{a}}$ \\
\hline Diagnosis (MCS) & VS/UWS & -1.02 & 0 & $0.36(0.07-1.79)$ \\
\hline CRS-R & & 1.29 & 0.58 & $3.64(1.27-10.45)^{c}$ \\
\hline DRS & & -0.35 & -0.17 & $0.70(0.37-1.32)$ \\
\hline EEG background (alpha) & Slow & 0.16 & 0.16 & $1.18(0.41-3.36)$ \\
\hline EEG-R eye (present) & Absent & 1.65 & 1.15 & $5.21(1.45-18.75)^{c}$ \\
\hline EEG-R acoustic (present) & Absent & 0.92 & 0.57 & $2.51(0.76-8.24)$ \\
\hline
\end{tabular}

Abbreviations: $\mathrm{Cl}$ = confidence interval; CRS-R = Coma Recovery Scale-Revised; DRS = Disability Rating Scale; EEG-R = EEG reactivity; MCS = minimally conscious state; OR = odds ratio; TPI = time postinjury; VS/UWS = vegetative state/unresponsive wakefulness syndrome.

Out of 135 patients included in the analysis (VS/UWS = 68; MCS =67), 69 improved at 6 months after brain injury (VS/UWS = 26; MCS = 43).

a Significant factors and relative OR. 
and acoustic reactivity at study entry were not. In this case, the bootstrapping procedure was only slightly biased (biases ranging from -0.31 to 0.34 ). The Hosmer-Lemeshow test for the logistic regression model indicated a good model fit ( $p=$ 0.77). Predictors in the model accounted for the $55.2 \%$ of variability in the model (Nagelkerke pseudo- $R^{2}=0.552$ ), and AUC was 0.88 (0.83-0.94). The LASSO model again provided a similar model fit accuracy (79.2\%) and eliminated from the model only etiology and clinical diagnosis (table 6), thus corroborating previous findings.

\section{Discussion}

This multicenter, prospective study enrolled a cohort of 147 patients with prolonged VS/UWS and MCS to identify prognostic indices for clinical improvement at 6 months after traumatic or nontraumatic brain injury. As evidence of clinical improvement, we considered both minimal improvement (i.e., the transition from VS/UWS to MCS) and full recovery of consciousness as study outcomes. Emergence from DoC results in improved functioning and quality of life and is meaningful for planning patient care and rehabilitation management. Even minimal improvement occurring by 6 months after injury can be important for the family ${ }^{5}$ and for identifying patients in MCS with higher likelihood of further clinical improvement. ${ }^{33}$ The same choice has been adopted in a recent meta-analysis showing that neurophysiologic methods are significantly more successful in predicting minimal improvement (i.e., the transition from VS/UWS to MCS) than recovery of full consciousness. ${ }^{14}$ Our findings showed that younger age, shorter time postinjury, higher CRS-R total score, and presence of EEG reactivity to eye opening seem to be associated with better outcome.

At study entry, the 2 diagnostic groups (i.e., VS/UWS and MCS) significantly differed with regards to their level of behavioral responsiveness as assessed by CRS-R and DRS-R total scores but also for responsiveness to nociceptive stimuli, as measured by NCS-R. This last finding is consistent with recent data showing a strong positive relation between responsiveness to nociception (i.e., NCS-R total score) and the CRS-R total score in a cohort of patients with DoC. ${ }^{28}$

At baseline, the 2 diagnostic groups also differed significantly for predominant EEG background activity, since poor EEG organization was more frequently observed in patients in VS/ UWS, whereas normal and mildly abnormal EEG activities, featuring a greater amount of alpha rhythm, were more frequent in patients in MCS. These findings are consistent with previous studies showing a possible diagnostic value of standard EEG in patients with DoC. ${ }^{12,21,29,30}$ It is worth mentioning that the same standardized nociceptive stimuli used in the NCS-R protocol did not determine different EEG responses in the 2 diagnostic groups. This apparent discrepancy could be ascribed to the use of nociceptive stimulation that was insufficient for determining detectable changes in (EEG) cortical activity.
Indeed, it has been shown that in patients in coma, EEG reactivity to pain can be best elicited by pain stimuli not used in the present study. ${ }^{31}$ Future studies might take into account this methodologic issue, and control for different types of nociceptive stimulation with varying levels of intensity and site of stimulation in patients with DoC. Finally, the P300 component on long-latency ERPs, investigating cognitive processes such as stimulus evaluation and categorization, was significantly more frequent in MCS than in VS/UWS, likely owing to relatively preserved attention abilities allowing discrimination of rare tones in an oddball paradigm in some patients in MCS. ${ }^{32}$

In our study, prognosis at 6 months postonset was substantially better in patients in MCS compared to patients in VS/UWS, in terms of both clinical improvements and survival. These findings are consistent with data reported in previous long-term outcome studies on DoC. ${ }^{33-36}$ Utilizing logistic regression analysis, we observed that younger age and shorter time since brain injury were significant predictors of a better outcome. Many previous studies ${ }^{1,10,11,36-38}$ found that older age was associated with a lower likelihood of recovery, likely due to lower age-related brain plasticity ${ }^{39}$ and worse general premorbid health conditions. ${ }^{40}$ The significant effect of time from injury at baseline is potentially related to the fact that patients with more severe brain injuries are usually admitted later to the rehabilitation settings in which the large majority of the present sample was enrolled. ${ }^{38,41-44}$

Besides these demographic and anamnestic indicators of better outcome, we found a significant role of the CRS-R total score in predicting better clinical evolution. The present findings supported the prognostic validity of CRS-R total score, in keeping with previous short-term ${ }^{11}$ and long-term ${ }^{10,45}$ longitudinal studies on individuals with DoC. Moreover, it is important to emphasize that age, time from injury, and CRS-R total score remained significant outcome predictors after accounting for covariates such as clinical diagnosis, etiology of brain injury, and functional disability level, which were considered significant outcome predictors in previous studies. $1,6,33,36-38,41,42$

One important finding of the present study was that EEG reactivity to eye opening, but not presence of P300 on ERP, discriminated patients who improved from patients who did not improve or had died at 6 months after the brain injury. A recent meta-analysis ${ }^{14}$ on empirical studies investigating the prognostic parameters of neurophysiologic variables (including EEG and ERP) highlighted that overall neurophysiologic data predicted the transition from VS/UWS to MCS substantially better than the transition from VS/UWS or MCS to emergence from MCS (i.e., the recovery of consciousness), whereas EEG changes to different kinds of stimuli and tasks were the only significant predictors in studies in which the 2 improvement criteria were considered cumulatively. Thus, the present study fits with the meta-analysis conclusion, since EEG reactivity predicted the 2 improvement criteria (i.e., "improved" outcome included minimal clinical improvement and regaining full consciousness). The temporary EEG alpha blocking in 
response to eye opening is related to basic thalamo-cortical system $^{46}$ thought to be involved in consciousness circuitry. ${ }^{47}$

The present findings are inconsistent with previous outcome studies showing that the presence of P300 on ERP can help clinicians to predict the recovery of consciousness in individuals with DoC. ${ }^{48,49}$ The poor prognostic value of ERP in our cohort of patients might be ascribed to the lower number of patients in whom ERPs were recorded $(n=75)$ or to the fact that an association of ERP with outcome at univariate analysis decreased in the regression analysis in which other strong predictors were simultaneously entered.

The present study has several limitations. First, the relatively small sample size did not allow us to search for predictors of outcome in the 2 diagnostic groups (i.e., VS/UWS and MCS) separately. For the same reason, we could not compare the prognostic factors for the 3 possible conditions of outcome (recovery of consciousness for patients in MCS, recovery of consciousness for patients in VS/UWS, and transition to MCS for patients in VS/ UWS), whereas it has been shown that prognostic factors might differentially affect each of them. ${ }^{14}$ Future multicenter studies should enroll a larger sample of patients to address these issues.

Second, neurophysiologic findings were not available in a relatively small group of patients (i.e., EEG background activity = 8; $\mathrm{EEG}$ reactivity to eye opening $=9$, to tactile stimuli $=17$, to acoustic stimuli $=7$, to nociceptive stimuli $=18$, to IPS $=14$; $\mathrm{SEP}=61$; ERP $=72$ ) mainly because of logistical challenges (e.g., lack of dedicated equipment, human resources, or time constraints) and technical issues (e.g., movement artifacts). Notwithstanding this limitation, we continue to promote the use of multimodal neurophysiologic evaluations whenever possible for improving prognostication in patients with DoC.

Further studies might also consider using self-referential auditory stimuli (e.g., patient's own name) as target stimuli in the ERP oddball paradigm. The oddball paradigm used here (rare vs frequent tones) could discriminate patients of the 2 groups at baseline and had a univariate association with better outcome, but self-referential stimuli could be more efficient for eliciting the P300 in patients with DoC. ${ }^{32,48,50}$

This study represents a first international, multicenter attempt to concurrently evaluate the prognostic value of demographic, anamnestic, clinical, and neurophysiologic data in patients with prolonged DoC. By applying standardized multimodal assessment protocols in patients in VS/UWS and MCS, we found that younger age, shorter time postinjury, higher level of responsiveness/consciousness, as measured by the CRS-R total score, and presence of EEG reactivity to eye opening could predict better outcome at 6 months after severe brain injury. These prognostic factors are feasible to record in intensive and rehabilitation care settings, can be analyzed by trained medical professionals without sophisticated technical tools, can be repeated at bedside, and are not time-consuming or expensive. The prognostic value of such indices should be investigated at 12

months and 24 months after onset to determine their relevance in predicting longer-term outcomes. This multicenter international study will hopefully serve as a starting point to stimulate further research that drives international consensus regarding standardization of prognostic procedures in the clinical care of individuals with prolonged DoC. Such prognostic procedures could help clinicians to identify people with DoC most suitable for tailored rehabilitation programs and therapeutic interventions.

\section{Acknowledgment}

The complete list of participating centers is as follows: ICS Maugeri (intensive specialized rehabilitation unit [ISRU]; Italy), University Hospital of Liege (Neurology Department; Belgium), IRCCS Fondazione Santa Lucia (ISRU; Italy), CHN William Lennox (ISRU; Belgium), Massachusetts General Hospital (intensive care unit [ICU]; USA), University of Athens Medical School (Neurology Department; Greece), Servicio de Neurorehabilitaciòn y Daño Cerebral Hospitales NISA (ISRU; Spain), IRCCS Don Gnocchi Institute (ISRU; Italy), Neurorehab Unit “E. Viglietta” (ISRU; Italy), Gleneagles Medini Hospital (ICU; Malaysia), HABILITA (ISRU; Italy), Fondazione Istituto "G. Giglio” (ISRU; Italy). The authors thank Ginger Vazquez for organizing IBIA-DoC SIG teleconferences, Drs. Giulia Ferri and Sara Schiattone for their help in collecting data, and patients' legal guardians for their participation in the project.

\section{Study funding}

This work was supported by grants from the European Union's Horizon 2020 research and innovation program under the Marie Skłodowska-Curie grant agreement 778234-DoCMA project, the NIH National Institute of Neurologic Disorders and Stroke (K23NS094538, R21NS109627, RF1NS115268), the NIH Director's Office (DP2HD101400), the James S. McDonnell Foundation, the Tiny Blue Dot Foundation, the European Union's Horizon 2020 Framework Programme for Research and Innovation under Specific Grant Agreement 785907 (Human Brain Project SGA2), the Luminous project (EU-H2020-fetopenga686764), the Belgian National Funds for Scientific Research (FRS-FNRS), and the Italian Ministry of Health (Current research program 2016-2017).

\section{Disclosure}

The authors report no disclosures relevant to the manuscript. Go to Neurology.org/N for full disclosures.

\section{Publication history}

Received by Neurology September 1, 2019. Accepted in final form March 20, 2020.

\section{Appendix 1 Authors}

\begin{tabular}{lll}
\hline Name & Location & Contribution \\
\hline $\begin{array}{l}\text { Anna } \\
\text { Estraneo, MD }\end{array}$ & IRCCS Don Gnocchi & $\begin{array}{l}\text { Design of the study, } \\
\text { Foundation } \\
\text { of the data, drafting and } \\
\text { revising the manuscript for } \\
\text { intellectual content }\end{array}$
\end{tabular}


Appendix 1 (continued)

\begin{tabular}{lll}
\hline Name & Location & Contribution \\
\hline $\begin{array}{l}\text { Salvatore } \\
\text { Fiorenza, }\end{array}$ & Maugeri ICS, Italy & $\begin{array}{l}\text { Major role in the collection } \\
\text { of neurophysiologic data, } \\
\text { NphT }\end{array}$ \\
& & $\begin{array}{l}\text { checking and collecting the } \\
\text { data from all participating } \\
\text { centers }\end{array}$
\end{tabular}

\begin{tabular}{ll}
\hline $\begin{array}{l}\text { Alfonso } \\
\text { Magliacano, } \\
\text { PsyD }\end{array}$ & $\begin{array}{l}\text { University of Campania L. } \\
\text { Vanvitelli, Italy }\end{array}$ \\
\hline $\begin{array}{l}\text { Rita } \\
\text { Formisano, } \\
\text { MD }\end{array}$ & $\begin{array}{l}\text { Fondazione Santa Lucia } \\
\text { IRCCS, Italy }\end{array}$ \\
\hline $\begin{array}{l}\text { Donatella } \\
\text { Mattia, MD, } \\
\text { PhD }\end{array}$ & Fondazione Santa Lucia \\
\hline
\end{tabular}

PhD

\begin{tabular}{ll}
\hline Antonello & IRCCS Fondazione Don \\
Grippo, MD & Carlo Gnocchi, Italy
\end{tabular}

Analysis and interpretation of the data, drafting the manuscript

Collection of the data, revision of the manuscript for the intellectual content

Collection of the data, revision of the manuscript for the intellectual content

\section{Supervision of}

neurophysiologic and clinical data, revision of the manuscript for intellectual content

\begin{tabular}{lll}
\hline $\begin{array}{l}\text { Anna Maria } \\
\text { Romoli, MD }\end{array}$ & $\begin{array}{l}\text { IRCCS Fondazione Don } \\
\text { Carlo Gnocchi, Italy }\end{array}$ & $\begin{array}{l}\text { Major role in patient } \\
\text { enrollment and collection } \\
\text { of the clinical data }\end{array}$ \\
\hline $\begin{array}{l}\text { Efthymios } \\
\text { Angelakis, } \\
\text { MD }\end{array}$ & $\begin{array}{l}\text { University of Athens } \\
\text { Medical School, Greece }\end{array}$ & $\begin{array}{l}\text { Collection of the data, } \\
\text { revision of the manuscript } \\
\text { for the intellectual content }\end{array}$ \\
\hline $\begin{array}{l}\text { Helena } \\
\text { Cassol, MD }\end{array}$ & $\begin{array}{l}\text { University and University } \\
\text { Hospital of Liège, Belgium }\end{array}$ & $\begin{array}{l}\text { Collection of the data, } \\
\text { revision of the manuscript } \\
\text { for the intellectual content }\end{array}$ \\
\hline $\begin{array}{l}\text { Aurore } \\
\text { Thibaut, PhD }\end{array}$ & $\begin{array}{l}\text { University and University } \\
\text { Hospital of Liège, Belgium }\end{array}$ & $\begin{array}{l}\text { Supervision of data } \\
\text { collection, revision of the } \\
\text { manuscript for intellectual } \\
\text { content }\end{array}$ \\
\hline
\end{tabular}

\begin{tabular}{ll}
\hline Olivia & University and University \\
Gosseries, & Hospital of Liège, Belgium \\
PhD &
\end{tabular}

Patients recruitment/ planning, collection of the data and supervision of the data collection, revision of the manuscript for intellectual content

\begin{tabular}{|c|c|c|}
\hline $\begin{array}{l}\text { Gianfranco } \\
\text { Lamberti, MD }\end{array}$ & $\begin{array}{l}\text { Neurorehabilitation and } \\
\text { Vegetative State Unit E. } \\
\text { Viglietta, Italy }\end{array}$ & $\begin{array}{l}\text { Collection of the data, } \\
\text { revision of the manuscript } \\
\text { for intellectual content }\end{array}$ \\
\hline $\begin{array}{l}\text { Enrique Noé, } \\
\text { MD, PhD }\end{array}$ & $\begin{array}{l}\text { NEURORHB, Servicio de } \\
\text { Neurorrehabilitación de } \\
\text { Hospitales Vithas, Spain }\end{array}$ & $\begin{array}{l}\text { Collection of the data, } \\
\text { revision of the manuscript } \\
\text { for intellectual content }\end{array}$ \\
\hline $\begin{array}{l}\text { Sergio } \\
\text { Bagnato, MD, } \\
\text { PhD }\end{array}$ & $\begin{array}{l}\text { Giuseppe Giglio } \\
\text { Foundation, Italy }\end{array}$ & $\begin{array}{l}\text { Collection of the data, } \\
\text { revision of the manuscript } \\
\text { for intellectual content }\end{array}$ \\
\hline $\begin{array}{l}\text { Brian L. } \\
\text { Edlow, MD }\end{array}$ & $\begin{array}{l}\text { Massachusetts General } \\
\text { Hospital, Boston }\end{array}$ & $\begin{array}{l}\text { Collection of the data, } \\
\text { revision of the manuscript } \\
\text { for intellectual content }\end{array}$ \\
\hline $\begin{array}{l}\text { Camille } \\
\text { Chatelle, PhD }\end{array}$ & $\begin{array}{l}\text { Massachusetts General } \\
\text { Hospital, Boston }\end{array}$ & $\begin{array}{l}\text { Collection of the data, } \\
\text { revision of the manuscript } \\
\text { for the intellectual content }\end{array}$ \\
\hline $\begin{array}{l}\text { Nicolas } \\
\text { Lejeune, MD }\end{array}$ & $\begin{array}{l}\text { CHN William Lennox, } \\
\text { Belgium }\end{array}$ & $\begin{array}{l}\text { Collection of the data, } \\
\text { revision of the manuscript } \\
\text { for the intellectual content }\end{array}$ \\
\hline $\begin{array}{l}\text { Vigneswaran } \\
\text { Veeramuthu, } \\
\text { PhD }\end{array}$ & $\begin{array}{l}\text { University of Reading, } \\
\text { Malaysia }\end{array}$ & $\begin{array}{l}\text { Collection of } \\
\text { the data, revision } \\
\text { of the manuscript for } \\
\text { intellectual content }\end{array}$ \\
\hline
\end{tabular}

Appendix 1 (continued)

\begin{tabular}{lll}
\hline Name & Location & Contribution \\
\hline $\begin{array}{l}\text { Michelangelo } \\
\text { Bartolo, MD, } \\
\text { PhD }\end{array}$ & $\begin{array}{l}\text { HABILITA Zingonia/ } \\
\text { Ciserano, Italy }\end{array}$ & $\begin{array}{l}\text { Collection of the data, } \\
\text { revision of the manuscript } \\
\text { for intellectual content }\end{array}$ \\
\hline $\begin{array}{l}\text { Jlenia Toppi, } \\
\text { PhD }\end{array}$ & $\begin{array}{l}\text { Sapienza University of } \\
\text { Rome, Italy }\end{array}$ & $\begin{array}{l}\text { Collection of the } \\
\text { neurophysiologic data and } \\
\text { analysis of the ERP data }\end{array}$ \\
\hline $\begin{array}{l}\text { Nathan } \\
\text { Zasler, MD }\end{array}$ & $\begin{array}{l}\text { Concussion Care Centre } \\
\text { of Virginia }\end{array}$ & $\begin{array}{l}\text { Revision of the manuscript } \\
\text { for intellectual content }\end{array}$ \\
\hline $\begin{array}{l}\text { Caroline } \\
\text { Schnakers, } \\
\text { PhD }\end{array}$ & $\begin{array}{l}\text { Casa Colina Hospital and } \\
\text { Centers for Healthcare, }\end{array}$ & $\begin{array}{l}\text { Revision of the manuscript } \\
\text { for intellectual content }\end{array}$ \\
\hline
\end{tabular}

\begin{tabular}{lll}
\hline Luigi Trojano, & University of Campania L. & $\begin{array}{l}\text { Analysis and } \\
\text { interpretation of the data, } \\
\text { Vanvitelli, Italy }\end{array}$ \\
& revision of the manuscript
\end{tabular}
for intellectual content

Appendix 2 Coinvestigators

\begin{tabular}{|c|c|c|c|}
\hline Name & Location & Role & Contribution \\
\hline $\begin{array}{l}\text { Orsola Masotta, } \\
\text { PsyD }\end{array}$ & Maugeri ICS, Italy & $\begin{array}{l}\text { Site } \\
\text { investigator }\end{array}$ & $\begin{array}{l}\text { Major role in collecting } \\
\text { and interpreting clinical } \\
\text { data }\end{array}$ \\
\hline $\begin{array}{l}\text { Marianna } \\
\text { Contrada, PsyD }\end{array}$ & $\begin{array}{l}\text { Fondazione Santa } \\
\text { Lucia IRCCS, Italy }\end{array}$ & $\begin{array}{l}\text { Site } \\
\text { investigator }\end{array}$ & $\begin{array}{l}\text { Patient enrollment, } \\
\text { collection and } \\
\text { interpretation of clinical } \\
\text { data }\end{array}$ \\
\hline $\begin{array}{l}\text { Maenia } \\
\text { Scarpino, MD }\end{array}$ & $\begin{array}{l}\text { IRCCS Fondazione } \\
\text { Don Carlo Gnocchi, } \\
\text { Italy }\end{array}$ & $\begin{array}{l}\text { Site } \\
\text { investigator }\end{array}$ & $\begin{array}{l}\text { Collecting and } \\
\text { interpreting } \\
\text { neurophysiologic data }\end{array}$ \\
\hline Joan Ferri, PhD & $\begin{array}{l}\text { NEURORHB, Servicio } \\
\text { de } \\
\text { Neurorrehabilitación } \\
\text { de Hospitales Vithas, } \\
\text { Spain }\end{array}$ & $\begin{array}{l}\text { Site } \\
\text { investigator }\end{array}$ & $\begin{array}{l}\text { Collecting and } \\
\text { interpreting clinical } \\
\text { data }\end{array}$ \\
\hline $\begin{array}{l}\text { Cristina } \\
\text { Boccagni, MD }\end{array}$ & $\begin{array}{l}\text { Giuseppe Giglio } \\
\text { Foundation, Italy }\end{array}$ & $\begin{array}{l}\text { Site } \\
\text { investigator }\end{array}$ & $\begin{array}{l}\text { Collecting and } \\
\text { interpreting clinical } \\
\text { data }\end{array}$ \\
\hline $\begin{array}{l}\text { Yelena G. } \\
\text { Bodien, PhD }\end{array}$ & $\begin{array}{l}\text { Massachusetts } \\
\text { General Hospital, } \\
\text { Boston }\end{array}$ & $\begin{array}{l}\text { Site } \\
\text { investigator }\end{array}$ & $\begin{array}{l}\text { Collecting and } \\
\text { interpreting clinical } \\
\text { data }\end{array}$ \\
\hline $\begin{array}{l}\text { Devaraj } \\
\text { Pancharatnam, } \\
\text { MD, FRCS } \\
\text { (Neurosurg) }\end{array}$ & $\begin{array}{l}\text { University of Reading, } \\
\text { Malaysia }\end{array}$ & $\begin{array}{l}\text { Site } \\
\text { investigator }\end{array}$ & $\begin{array}{l}\text { Collecting and } \\
\text { interpreting clinical } \\
\text { data, technical } \\
\text { assistance, contribution } \\
\text { of study participants }\end{array}$ \\
\hline Hend Aabid, MD & $\begin{array}{l}\text { HABILITA Zingonia/ } \\
\text { Ciserano, Italy }\end{array}$ & $\begin{array}{l}\text { Site } \\
\text { investigator }\end{array}$ & $\begin{array}{l}\text { Collecting and } \\
\text { interpreting clinical } \\
\text { data }\end{array}$ \\
\hline
\end{tabular}

\section{References}

1. Multi-Society Task Force Report on PVS. Medical aspects of the persistent vegetative state. N Engl J Med 1994;330:1499-1508.

2. Laureys $\mathrm{S}$, Celesia G, Cohadon F, et al. Unresponsive wakefulness syndrome: a new name for the vegetative state or apallic syndrome. BMC Med 2010;8:68.

3. Giacino JT, Ashwal S, Childs N, et al. The minimally conscious state: definition and diagnostic criteria. Neurology 2002;58:349-353.

4. Giacino JT, Katz DI, Schiff ND, et al. Practice guideline update recommendations summary: disorders of consciousness: report of the Guideline Development, Dissemination, and Implementation Subcommittee of the American Academy of Neurology; the American Congress of Rehabilitation Medicine; and the National Institute on Disability, Independent Living, and Rehabilitation Research. Neurology 2018;91:450-460. 
5. Fins JJ, Bernat JL. Ethical, palliative, and policy considerations in disorders of consciousness. Neurology 2018;91:471-475.

6. Estraneo A, Trojano L. Prognosis of disorders of consciousness. In: Schnakers C, Laureys S, eds. Coma and Disorders of Consciousness. Berlin: Springer; 2018:17-36.

7. Daltrozzo J, Wioland N, Mutschler V, Kotchoubey B. Predicting coma and other low responsive patients outcome using event related brain potentials: a meta-analysis. Clin Neurophysiol 2007;118:606-614.

8. Scarpino M, Lanzo G, Lolli F, et al. Neurophysiological and neuroradiological multimodal approach for early poor outcome prediction after cardiac arrest. Resuscitation 2018;129:114-120.

9. Robinson LR, Micklesen PJ, Tirschwell DL, Lew HL. Predictive value of somatosensory evoked potentials for awakening from coma. Crit Care Med 2003;31:960-967.

10. Estraneo A, Moretta P, Loreto V, et al. Predictors of recovery of responsiveness in prolonged anoxic vegetative state. Neurology 2013;80:464-470.

11. Portaccio E, Marrocchesi A, Romoli AM, et al. Score on Coma Recovery ScaleRevised at admission predicts outcome at discharge in intensive rehabilitation after severe brain injury. Brain Inj 2018;32:730-734

12. Bagnato S, Boccagni C, Prestandrea C, Sant'Angelo A, Castiglione A, Galardi G. Prognostic value of standard EEG in traumatic and non-traumatic disorders of consciousness following coma. Clin Neurophysiol 2010;121:274-280.

13. Bagnato S, Boccagni C, Sant'Angelo A, Prestandrea C, Mazzilli R, Galardi G. EEG predictors of outcome in patients with disorders of consciousness admitted for intensive rehabilitation. Clin Neurophysiol 2015;126:959-966.

14. Kotchoubey B, Pavlov YG. A systematic review and meta-analysis of the relationship between brain data and the outcome in disorders of consciousness. Front Neurol 2018;9:315.

15. Giacino JT, Kalmar K, Whyte J. The JFK coma recovery scale-revised: measurement characteristics and diagnostic utility. Arch Phys Med Rehabil 2004;85:2020-2029.

16. Estraneo A, Moretta P, Cardinale V, et al. A multicentre study of intentional behavioural responses measured using the Coma Recovery Scale-Revised in patients with minimally conscious state. Clin Rehabil 2015;29:803-808.

17. Pascarella A, Fiorenza $S$, Masotta $\mathrm{O}$, et al. Multicentre registry of brain-injured patients with disorder of consciousness: rationale and preliminary data. Funct Neurol 2018;33:19-30.

18. Wannez S, Heine L, Thonnard M, Gosseries O, Laureys S; Coma Science Group collaborators. The repetition of behavioral assessments in diagnosis of disorders of consciousness. Ann Neurol 2017;81:883-889.

19. Chatelle C, Majerus S, Whyte J, Laureys S, Schnakers C. A sensitive scale to assess nociceptive pain in patients with disorders of consciousness. J Neurol Neurosurg Psychiatry 2012;83:1233-1237.

20. Rappaport M, Hall KM, Hopkins K, et al. Disability Rating Scale for severe head trauma: coma to community. Arch Phys Med Rehabil 1982;63:118-123.

21. Estraneo A, Loreto V, Guarino I, et al. Standard EEG in diagnostic process of prolonged disorders of consciousness. Clin Neurophysiol 2016;127:2379-2385.

22. Striano S, Meo R, Bilo L, et al. The use of EEG activating procedures in epileptology. Acta Neurol 1992;14:275-289.

23. Cruccu G, Aminoff MJ, Curio G, et al. Recommendations for the clinical use of somatosensory-evoked potentials. Clin Neurophysiol 2008;119:1705-1719.

24. Duncan CC, Barry RJ, Connolly JF, et al. Event related potentials in clinical research: guidelines for eliciting, recording, and quantifying mismatch negativity, P300, and N400. Clin Neurophysiol 2009;120:1883-1908.

25. Schnakers C, Perrin F, Schabus M, et al. Voluntary brain processing in disorders of consciousness. Neurology 2008;71:1614-1620.

26. Kennedy P. A Guide to Econometrics, 5th ed. Cambridge, MA: The MIT Press; 2003.

27. Leblanc G, Boutin A, Shemilt M, et al. Incidence and impact of withdrawal of lifesustaining therapies in clinical trials of severe traumatic brain injury: a systematic review. Clin Trials 2018;15:398-412.
28. Chatelle C, Hauger S, Martial C, et al. Assessment of nociception and pain in patients in an unresponsive or minimally conscious state after acquired brain injury: the relationship between the Coma Recovery Scale-Revised and the Nociception Coma Scale-Revised. Arch Phys Med Rehabil 2018;99:1755-1762.

29. Forgacs PB, Conte MM, Fridman EA, Voss HU, Victor JD, Schiff ND. Preservation of electroencephalographic organization in patients with impaired consciousness and imaging-based evidence of command-following. Ann Neurol 2014;76:869-879.

30. Toppi J, Mattia D, Risetti M, Formisano R, Babiloni F, Astolfi L. Testing the significance of connectivity networks: comparison of different assessing procedures. IEEE Trans Biomed Eng 2016;63:2461-2473.

31. Tsetsou S, Novy J, Oddo M, Rossetti AO. EEG reactivity to pain in comatose patients: importance of the stimulus type. Resuscitation 2015;97:34-37.

32. Risetti M, Formisano R, Toppi J, et al. On ERPs detection in disorders of consciousness rehabilitation. Front Hum Neurosci 2013;7:775.

33. Luauté J, Maucort-Boulch D, Tell L, et al. Long-term outcomes of chronic minimally conscious and vegetative states. Neurology 2010;75:246-252.

34. Steppacher I, Kaps M, Kissler J. Will time heal? A long-term follow-up of severe disorders of consciousness. Ann Clin Transl Neurol 2014;1:401-408.

35. Faugeras F, Rohaut B, Valente M, et al. Survival and consciousness recovery are better in the minimally conscious state than in the vegetative state. Brain Inj 2018;32:72-77.

36. Estraneo A, Loreto V, Masotta O, Pascarella A, Trojano L. Do medical complications impact long-term outcomes in prolonged disorders of consciousness? Arch Phys Med Rehabil 2018;99:2523-2531.

37. Estraneo A, Moretta P, Loreto V, Lanzillo B, Santoro L, Trojano L. Late recovery after traumatic, anoxic, or hemorrhagic long-lasting vegetative state. Neurology 2010;75 239-245.

38. Baricich A, de Sire A, Antoniono E, et al. Recovery from vegetative state of patients with a severe brain injury: a 4-year real-practice prospective cohort study. Funct Neurol 2017;32:131-136

39. Gutchess A. Plasticity of the aging brain: new directions in cognitive neuroscience. Science 2014;346:579-582.

40. Mosenthal AC, Lavery RF, Addis M, et al. Isolated traumatic brain injury: age is an independent predictor of mortality and early outcome. J Trauma 2002;52:907-911.

41. Eilander HJ, Wijnen VJM, Scheirs JGM, De Kort PLM, Prevo AJH. Children and young adults in a prolonged unconscious state due to severe brain injury: outcome after an early intensive neurorehabilitation programme. Brain Inj 2005;19:425-436.

42. Whyte J, Gosseries O, Chervoneva I, et al. Predictors of short-term outcome in braininjured patients with disorders of consciousness. Prog Brain Res 2009;177:63-72.

43. Formisano R, Azicnuda E, Sefid MK, Zampolini M, Scarponi F, Avesani R. Early rehabilitation: benefits in patients with severe acquired brain injury. Neurol Sci 2017; 38:181-184.

44. Pascarella A, Trojano L, Loreto V, Bilo L, Moretta P, Estraneo A. Long-term outcome of patients with disorders of consciousness with and without epileptiform activity and seizures: a prospective single centre cohort study. J Neurol 2016;263:2048-2056.

45. Estraneo A, De Bellis F, Masotta O, et al. Demographical and clinical indices for longterm evolution of patients in vegetative or in minimally conscious state. Brain Inj 2019;33:1633-1639.

46. Berger H. Über das Elektrenkephalogramm des Menschen [On the electroencephalogram of men]. Arch Psychiatr Nervenkr 1929;87:527-570.

47. Schiff ND. Recovery of consciousness after brain injury: a mesocircuit hypothesis. Trends Neurosci 2010;33:1-9.

48. Steppacher I, Eickhoff S, Jordanov T, Kaps M, Witzke W, Kissler J. N400 predicts recovery from disorders of consciousness. Ann Neurol 2013;73:594-602.

49. Zhang Y, Li R, Du J, Huo S, Hao J, Song W. Coherence in P300 as a predictor for the recovery from disorders of consciousness. Neurosci Lett 2017;653:332-336.

50. Cheng L, Gosseries $\mathrm{O}$, Ying L, et al. Assessment of localisation to auditory stimulation in post-comatose states: use the patient's own name. BMC Neurol 2013;13:27. 


\section{Neurology}

\section{Multicenter prospective study on predictors of short-term outcome in disorders of consciousness}

Anna Estraneo, Salvatore Fiorenza, Alfonso Magliacano, et al.

Neurology 2020;95;e1488-e1499 Published Online before print July 13, 2020

DOI 10.1212/WNL.0000000000010254

This information is current as of July 13, 2020

\section{Updated Information \&} Services

References

Subspecialty Collections

Permissions \& Licensing

Reprints including high resolution figures, can be found at: http://n.neurology.org/content/95/11/e1488.full

This article cites 48 articles, 9 of which you can access for free at: http://n.neurology.org/content/95/11/e1488.full\#ref-list-1

This article, along with others on similar topics, appears in the following collection(s):

All Cerebrovascular disease/Stroke

http://n.neurology.org/cgi/collection/all_cerebrovascular_disease_strok e

All Clinical Neurology

http://n.neurology.org/cgi/collection/all_clinical_neurology

All clinical neurophysiology

http://n.neurology.org/cgi/collection/all_clinical_neurophysiology

All Rehabilitation

http://n.neurology.org/cgi/collection/all_rehabilitation

Prognosis

http://n.neurology.org/cgi/collection/prognosis

Information about reproducing this article in parts (figures,tables) or in its entirety can be found online at:

http://www.neurology.org/about/about_the_journal\#permissions

Information about ordering reprints can be found online:

http://n.neurology.org/subscribers/advertise

Neurology ${ }^{\circledR}$ is the official journal of the American Academy of Neurology. Published continuously since 1951 , it is now a weekly with 48 issues per year. Copyright Copyright (C) 2020 The Author(s). Published by Wolters Kluwer Health, Inc. on behalf of the American Academy of Neurology.. All rights reserved. Print ISSN: 0028-3878. Online ISSN: 1526-632X.

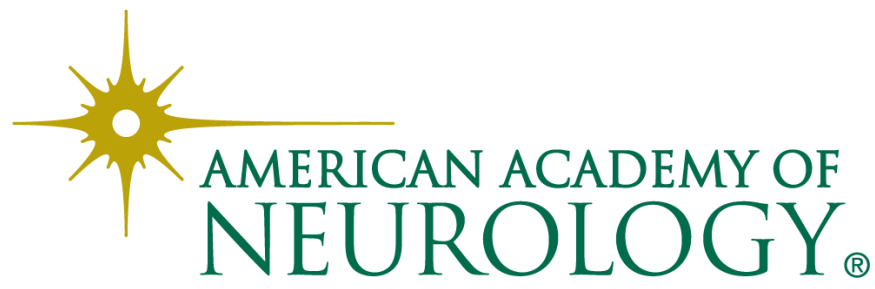

